\title{
ANIMAL HABITAT QUALITY AND ECOSYSTEM FUNCTIONING: EXPLORING SEASONAL PATTERNS USING NDVI
}

\author{
Thorsten Wiegand, ${ }^{1,4}$ Javier Naves, ${ }^{2,5}$ Martín F. Garbulsky, ${ }^{3,6}$ and Néstor Fernández ${ }^{1}$ \\ ${ }^{1}$ UFZ Helmholtz Centre for Environmental Research-UFZ, Department of Ecological Modelling, P.O. Box 500136, \\ 04301 Leipzig, Germany \\ ${ }^{2}$ Estación Biológica de Doñana, CSIC, Av. María Luisa s/n, Pabellón de Perú, 41013 Sevilla, Spain \\ ${ }^{3}$ LART, Departamento de Producción Animal, Facultad de Agronomía, Universidad de Buenos Aires, Av. San Martin 4453, \\ C1417DSE Buenos Aires, Argentina
}

\begin{abstract}
Many animal species have developed specific evolutionary adaptations to survive prolonged periods of low energy availability that characterize seasonal environments. The seasonal course of primary production, a major aspect of ecosystem functioning, should therefore be an important factor determining the habitat quality of such species. We tested this hypothesis by analyzing the relationship between habitat quality and ecosystem functioning for brown bears (Ursus arctos), a species showing hyperphagia and hibernation as evolutionary adaptation to seasonal peaks and bottlenecks in ecosystem productivity, respectively. Our unique long-term data set comprised data from two brown bear populations in northern Spain on historical presence, current presence, and reproduction. The data were classified on a grid of $5 \times 5 \mathrm{~km}$ pixels into five classes: frequent reproduction, sporadic reproduction, frequent presence, sporadic presence, and recent extinction. We used the longterm average of the seasonal course of NDVI (normalized difference vegetation index) as a proxy for ecosystem functioning and investigated the relationship between habitat quality and ecosystem functioning with methods borrowed from statistical point-pattern analysis.

We found that brown bears indeed selected habitat with specific ecosystem functioning (i.e., the variance in all habitat classes was smaller than in the landscape overall) and the relationship between habitat quality and ecosystem functioning was ordered. First, the average distance in ecosystem functioning between two habitat classes was larger if the difference in habitat quality was larger. Second, habitat for which there was the greatest need (i.e., breeding habitat) occupied the narrowest niche regarding ecosystem functioning and showed the most pronounced seasonality. Progressively poorer classes occupied wider niches that partly overlapped those of better classes. This indicated that nonbreeding animals are less selective.

Our methodology provided new insight into the relationship between ecosystem functioning and habitat quality and could be widely applied to animal species living in seasonal environments. Because NDVI data are continuously collected, our methodology allows for continuous monitoring of changes in habitat quality due to global change.
\end{abstract}

Key words: brown bear; ecosystem functioning; endangered species; extinction; habitat quality; NDVI; northern Spain; point-pattern analysis; remote sensing; seasonality; Ursus arctos.

\section{INTRODUCTION}

A basic question in ecology is to understand the factors and processes determining the distribution and abundance of species in space and time (Brown et al. 1995, Greenwood et al. 1996). On biogeographic or continental scales, it is well established that seasonality and energetic constraints are important factors determining animal distribution and abundance, or life

Manuscript received 9 November 2006; revised 10 April 2007; accepted 12 April 2007; final version received 8 May 2007. Corresponding Editor: W. D. Koenig.

${ }^{4}$ E-mail: Thorsten.Wiegand@ufz.de

5 Present address: Departamento de Biología de Organismos y Sistemas, Universidad de Oviedo, Catedrático Rodrigo Uría s/n, Oviedo 33071, Spain.

${ }^{6}$ Present address: Unitat Ecofisiologia CSIC-CREAF, Facultat de Ciències, Campus Universitat Autònoma Barcelona, 08193 Bellaterra, Spain. history traits of populations (e.g., Boyce 1979, Koenig 1984, Lindstedt and Boyce 1985, Alerstam and Hedenström 1998, McLoughlin et al. 2000, Ferguson 2002, Humphries et al. 2002, Nilsen et al. 2005). A range of species have developed very specific evolutionary adaptations to track an annual productive pulse of specific amplitude, duration, and seasonality (Weiner 1992, Humphries et al. 2002). In extreme cases the animal needs to survive prolonged periods with almost zero energy available to harvest (i.e., bottlenecks; Humphries et al. 2004). Animal responses to seasonal energetic constrains include, for example, dormancy, migratory behavior, and hibernation (MacArthur 1959, Herrera 1978, Hellgren 1998, Pérez-Tris and Tellería 2002, Hurlbert and Haskell 2003). However, pulses in primary production not only influence animal behavior during the season of low energy availability but also may control the habitat quality for reproduction. For 
example, in mammals, such as the brown bear, adapted to low resource availability during winter and spring (Hellgren 1998), pregnant females do not feed for a long period of the year; thus breeding success depends critically on a pulse in energy availability for fat storage during the hyperphagia period in summer and fall (Mattson et al. 1991, Craighead et al. 1995, Hissa 1997, Inman and Pelton 2002).

Therefore, patterns in seasonal energy availability may influence not only species habitat at the distribution level, but also habitat quality at the local scales of home range selection and, ultimately, the population abundance. One common approach for the analysis of local species-environment relationships is the use of statistical models relating the distribution of species or communities to "static" environmental variables such as land cover (Mladenoff et al. 1995, Schadt et al. 2002), or topography (Hirzel et al. 2002, Nielsen et al. 2003). However, these approaches neglect the effect of temporal (seasonal) variability in the environment on the species' habitats. Some of these approaches have also included satellite-derived spectral indices, such as the normalized difference vegetation index (NDVI), which are used as a surrogate to describe vegetation structure or overall annual productivity and biomass (e.g., Mace et al. 1999, Osborne et al. 2001, Nielsen et al. 2002, 2003, Zinner et al. 2002).

Despite the wide use of NDVI data for classifying the vegetation structure in species habitat assessment (Kerr and Ostrovsky 2003), few studies have explored its potential for habitat evaluation in relation to functional attributes of the ecosystem. However, information derived from remotely sensed data can accurately represent functional attributes of the ecosystem (Paruelo et al. 2001). For example, NDVI correlates with aboveground net primary production, ANPP (Goward et al. 1994, Hobbs 1995, Paruelo et al. 1997, 2001, Pettorelli et al. 2005) and can be used to describe the dynamics of primary production (Lloyd 1990, Paruelo et al. 2001), one of the essential and most integrative functional attributes of ecosystems. In this article we follow Lloyd (1990) and use phenology, derived from the seasonal course of NDVI, to describe ecosystem functioning. In general, the relationship between the NDVI and vegetation productivity is well established (Pettorelli et al. 2005) and it is often assumed that NDVI correlates with seasonal average energy availability, for example, in elephants (Wittemyer et al. 2007), birds (Hurlbert and Haskell 2003), monkeys (Zinner et al. 2002), herbivores (Andersen et al. 2004, Garel et al. 2006), and carnivores (Herfindal et al. 2005, Nilsen et al. 2005). NDVI also has been used as direct measure of plant phenology to investigate the impact of seasonality and predictability in plant phenology for breeding synchrony of red deer (Loe et al. 2005) and to detect key periods of plant productivity determining animal performance (Pettorelli et al. 2006).
The seasonal course of NDVI pattern may provide additional information because ecosystem functioning is not necessarily correlated with vegetation structure. Structurally different vegetation units may have similar functioning, or structurally similar units may differ in functioning (Paruelo et al. 2001, Falge et al. 2002, Alcaraz et al. 2006).

Ecosystem functioning may be an important factor for habitat quality if the life cycle of the species requires, in addition to a total amount of energy, a specific temporal distribution of energy not captured by average values. We tested this hypothesis by analyzing the relationship between habitat quality and the seasonal dynamics of primary production for brown bears, a species evolutionarily adapted to seasonal fluctuations in ecosystem productivity. To this end, we formulated three working hypotheses to specify the type of habitat selection. The first hypothesis $\left(H_{1}\right)$ tests if the species indeed selects habitats with a specific ecosystem functioning. Next, we expected an ordered relationship between habitat quality and ecosystem functioning. We hypothesized that the average difference in ecosystem functioning between two habitat classes should be larger if the difference in habitat quality is larger $\left(\mathrm{H}_{2}\right)$. If the first and second hypotheses were confirmed, we further specified the type of habitat selection by qualitatively distinguishing between two extreme cases of habitat selection with respect to habitat quality: nested similarity and segregation. Under nested similarity (hypothesis $H_{3 i}$ ), we expected that habitat with the most excessive needs (i.e., breeding habitat) would require the most specific ecosystem functioning (i.e., the narrowest niche), whereas habitat selection of progressively poorer classes would become weaker (i.e., wider niches, overlapping those of better classes). In contrast, under the segregation (hypothesis $H_{3 i i}$ ), each habitat class would be related to a different, but specific, pattern of ecosystem functioning (i.e., nonoverlapping niches for each habitat class).

Here, we tested these hypotheses by using unique data on the contemporary and historic distribution and habitat use of brown bears (Ursus arctos) in two apparently isolated subpopulations in northern Spain (Wiegand et al. 1998, Naves et al. 2003). We classified our data on habitat use for each subpopulation into sequentially nested habitat classes ranging from breeding habitat, to habitat with observations but no breeding, to local extinction. To compare the seasonal NDVI patterns of the different classes, we used statistical methods of point-pattern analysis operating in a 12-dimensional NDVI space, where each month of the seasonal NDVI patterns contributes one dimension. We also investigated the relative contribution of the seasonal course of NDVI (i.e., temporal variability in productivity) and mean NDVI (mean productivity) to our results, and tested for possible type I error introduced by spatial autocorrelation. In addition, we used ordinal logistic regression models to find out which 
Areas with reproduction Areas with observations but no reproduction

- Regular (3-9 yr)
$\square$ Sporadic (1-2 yr) $\square$ Regular (3-10)

$\square$ Sporadic (1-2)
Areas with extinction

$\square$ Not present in 20 th century; present in 18 th century

$\square$ Not present in 18 th century; present in 14 th century

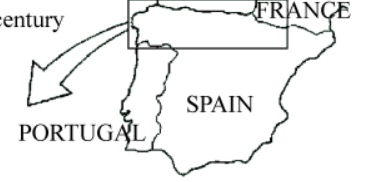

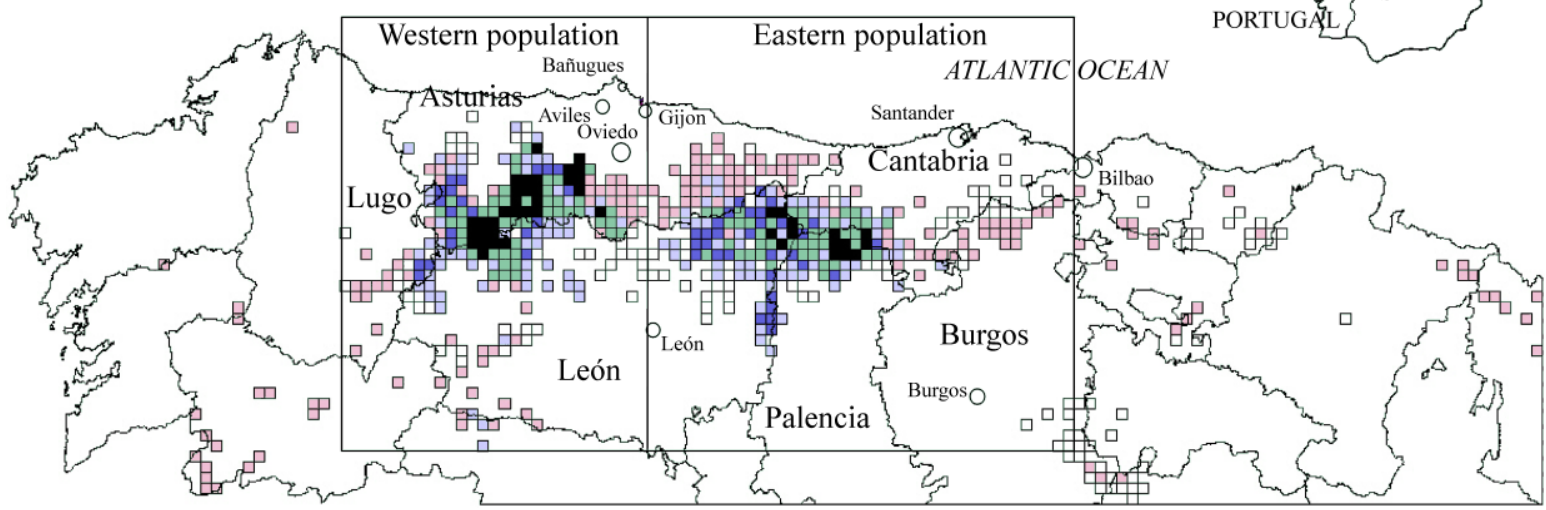

FIG. 1. Habitat classes based on data on reproduction, contemporary brown bear (Ursus arctos) observations, and historic presences. The two rectangles enclose the area of the western and the eastern population, and solid lines show the borders between provinces.

properties of the seasonal NDVI pattern explain differences among habitat classes.

\section{Methods}

\section{Study area and populations}

The area where the two brown bear subpopulations are located comprises a large part of the Cantabrian Mountains in the northwestern Iberian Peninsula (rectangle in Fig. 1) located between $4^{\circ}$ and $7^{\circ} \mathrm{W}$ longitude, and $42^{\circ}$ and $43^{\circ} \mathrm{N}$ latitude. Brown bears have been protected in Spain since 1973 and are listed in the National List of Threatened Species as being in serious danger of extinction (Servheen 1990). The two apparently isolated subpopulations occupy similar areas of $\sim 3700 \mathrm{~km}^{2}$ (Naves et al. 1999) and are remnants of a distribution that, during the 18th-19th centuries, still extended over the whole range of the Cantabrian Mountains (Nores 1988, Nores and Naves 1993; see Fig. 1).

High elevations and humidity facilitate abundant snow during winter. The north-facing slopes are under the influence of the Euro-siberian phytoclimatic, in which a cold-temperate ocean climate dominates, with high rainfall during the entire year, moderate sun radiation, and high cloudiness (Rivas-Martínez 1984). However, the south-facing slopes are under the influence of the mediterranean phytoclimatic region and the climate is characterized by hotter and drier summers, winter rainfall, and generally high sun radiation (RivasMartínez 1984).

Forest cover is more varied on north-facing slopes, with oak (Quercus petraea, $Q$. pyrenaica, and $Q$. rotundifolia), beech (Fagus sylvatica), and chestnut (Castanea sativa) trees, whereas on the south-facing slopes forest is dominated by deciduous durmast oak $(Q$. petraea, $Q$. pyrenaica) and beech. Past human activities have resulted in conversion of former forest into pasture and brushwood (Genista, Cytisus, Erica, and Calluna) and the current cover in areas with bear observations is $16.1 \% \pm 14.1 \%$ forest cover (mean $\pm \mathrm{SD}$ ) and $15.3 \% \pm$ $14.5 \%$ forest cover for the western and eastern population, respectively (Naves et al. 2003). Human density in areas with contemporaneous bear observations is relatively high: about 13.3 inhabitants $/ \mathrm{km}^{2}$ in the western population and 6.3 inhabitants $/ \mathrm{km}^{2}$ in the eastern population.

\section{Bear observation data}

Three different types of bear observation data were used, including (1) observations of females with cubs, (2) other observations of single or independent bears (tracks, scats, hair, and direct sightings), and (3) historical data.

Reproduction data.-Data on females with cubs were based on annual official counts performed between 1982 and 1993, with the exception of 1985, and were available from our data for 1994 and 1995. All official counts were exhaustively revised and documented in Naves et al. (1999). The observation data were mainly tracks and direct observations and were collected systematically, following the same procedure every year. In total, 417 valid observations of family groups were collected for the western population and 174 for the eastern population. On average, every family group was observed about five times. Note that family groups are usually well detectable in the Cantabrian Mountains because of low forest cover and high human density. More details on the data are provided in Appendix A.

Observation data.- The data set on bear observations, excluding observations of females with cubs, was based 
on systematic investigations on the distribution of brown bears in northern Spain (Naves et al. 1999) and was compiled between 1982 and 1991. The observations, mainly tracks, scats, hair, and direct sightings, were made by the research teams and by rangers, and were completed through interviews of local people (for more detail, see Appendix A). The total number of observations was 982 in the western population and 705 in the eastern population. Note that only one bear species is present in the Cordillera Cantabria (grizzly and black bears occur in many sites in North America together). This makes identification of tracks, scats, hair, and direct observations much easier.

Historical data.-Historical data on bear presence were compiled from various historic sources (Alfonso XI 1348, Madoz 1846-1850) and from recent authors (Nores 1988, Nores and Naves 1993, Torrente 1999). From the historic data, we used the more recent data from Madoz (1846-1850), which were completed with some anecdotal data from other sources (Appendix A: Figs. A1 and A2). Madoz (1846-1850) is a geographicalstatistical-historical dictionary that contains systematic information about villages and locations in Spain including, e.g., location, agricultural production, and prey species present in the area. Data on bear presenceabsence could be extracted from this source for a high number of villages in our study area (Appendix A: Fig. A2).

Spatial scale and grain of analysis.-We used a grid with a $5 \times 5 \mathrm{~km}$ pixel size to summarize all data on bear observations, sightings of females with cubs, NDVI, and landscape variables. This is an appropriate spatial grain that balances between a large-scale regional analysis, on the one hand, and differentiating NDVI data and environmental variables inside individual home ranges (which might be below $100 \mathrm{~km}^{2}$ ), on the other hand (see Appendix A).

We also selected the relatively coarse $25-\mathrm{km}^{2}$ grain to assure that pixels with non-observations were indeed areas with non-presence and that our observations were representative. It is important to note that the bear ranges in the Cantabrian Mountains are, in contrast to bear ranges in North America and Scandinavia, nonwilderness areas with high human densities and low forest cover. We therefore expect that the presence of bears, and especially of family groups, would be recognized in a $25-\mathrm{km}^{2}$ area within a decade, by the research team, by park rangers, or by local people. For the same reason, we expect that ranking of pixels into two coarse classes (low vs. high number of observations; low vs. high number of years where family groups were observed; see Classification of habitat use) reflects differences in habitat quality, circumventing potential problems due to unequal search effort in the different pixels.

With this $25-\mathrm{km}^{2}$ spatial grain, the total number of pixels with contemporary bear observations was 155 in the western population and 147 in the eastern popula- tion (Fig. 1) and the total number of pixels with reproduction (i.e., family groups) was 76 in the western and 55 in the eastern population (Fig. 1). In total, there were 573 pixels with historic bear presence recorded between the 14th and 19th century, of which 297 differed from the present distribution. We defined pixels with observations in the 18th century, but no contemporary observations, as "recent extinctions." We counted 79 pixels with recent extinction in the area of the western population (i.e., the left-hand rectangle in Fig. 1) and 100 pixels in the area of the eastern population (i.e., the right-hand rectangle in Fig. 1).

Classification of habitat use.-For the purpose of our analysis, we classified the pixels with evidence for brown bear presence into five classes (Fig. 1): (1) family groups were observed in a given pixel during three or more years, out of 13 study years (frequent reproduction); (2) family groups were observed in a given pixel during one or two years (sporadic reproduction); (3) no reproduction was observed, but there were more than two observations (frequent observations); (4) no reproduction was observed, but there were one or two observations (i.e., sporadic observations); and (5) bears were present in the 19th century but extinct in the 20th century (recent extinction). We selected this classification scheme to obtain a rough qualitative ranking (see Spatial scale and grain...) in habitat use with equilibrated sample sizes for the different classes. Because the maximum number of events in classes 1 and 3 was 31, we limited the sample size of the other classes to a maximum of 31 pixels (see Appendix A: Table A3). We removed pixels of classes 2,4 , and 5 to minimize the number of direct neighbors, which reduced the spatial autocorrelation to some extent.

\section{NDVI data}

We used AVHRR-NDVI data (Advanced Very High Resolution Radiometer-Normalized Difference Vegetation Index) from the period from January 1987 to December 2001 (data were not available between October 1994 and September 1995). The NDVI is a spectral index calculated from reflectance of vegetation in the near infrared and red portions of the electromagnetic spectrum that is linearly correlated with the fraction of the photosynthetically active radiation (PAR) intercepted by the vegetation (Asrar et al. 1984, Box et al. 1989, Sellers et al. 1994). Raw data at a 10-day temporal resolution and $1-\mathrm{km}$ spatial resolution were provided by the Laboratorio de Teledetección-Universidad de Valladolid (LATUV), Spain (for details on processing, see Appendix B). Raw NDVI values range from -1 to 1 , but LATUV rescaled the index from 0 to 200 , with values of $100-200$ representing increasing greenness and values $<100$ indicating non-vegetated areas such as snow, water, or bare soil. We transformed the original data to monthly composites with the $5 \times 5$ $\mathrm{km}$ resolution required for our analysis by averaging all of the pixels inside the $5 \times 5 \mathrm{~km}$ grid containing valid 
data for each of the three composites of each month. Next we calculated for each month $(1, \ldots 12)$ and each $25-\mathrm{km}^{2}$ pixel $i$ of our study area the long-term average $\mathrm{NDVI}_{i}$ (month), in the following called "seasonal pattern." By averaging over 25 pixels and 15 years, we considerably reduced the amount of missing data due to clouds and other error sources. The 15-year long-term averages were stationary (see Appendix B) and provided a good approximation of ecosystem functioning.

The 12 variables of the seasonal NDVI pattern represent only local properties $\left(25 \mathrm{~km}^{2}\right)$ of the landscape. However, larger-scale properties of the variables may be important because brown bear home ranges typically comprise several $25-\mathrm{km}^{2}$ pixels and also because our data measure population-level phenomena such as extinction, which operate at larger scales. To consider multiple scales, we calculated, from the $25-\mathrm{km}^{2}$ raster data, the average value of each variable in neighborhoods with radius $r=1, \ldots 4$ pixels (for details, see Schadt et al. 2002, Naves et al. 2003).

\section{Seasonal NDVI patterns of best brown bear habitat and of dominant vegetation types}

Before embarking on statistical analyses, we described the typical type of ecosystem functioning that bear family groups prefer by showing the seasonal NDVI patterns taken from the 11 pixels with the highest number of years with recorded reproduction and its averages. We also showed the seasonal NDVI patterns taken from the 11 pixels with the highest proportion of forest cover, cover of mediterranean scrubland (matorral), cover of reforestation, cover of agricultural land, and livestock units (grassland).

\section{Statistical Analyses}

\section{Distance metric to describe the difference between seasonal NDVI patterns}

We used concepts of the theory of point patterns to test hypotheses $H_{1}, H_{2}$, and $H_{3}$. Classical point-pattern analysis (Stoyan and Stoyan 1994, Diggle 2003) can be used to investigate, e.g., whether the mapped locations of two types of events are independent (as opposed to attraction or segregation), or whether one type of points is a random sample of the joined point pattern (as opposed to showing additional clustering or regularity). This is usually done by comparing spatial statistics, which are based on the distance between all pairs of points, to confidence limits determined through Monte Carlo simulation of realizations of an appropriate null model (Wiegand and Moloney 2004).

The seasonal NDVI pattern $\mathrm{NDVI}_{k}$ (month) of a given pixel $k$ and month $=1, \ldots 12$ defines a point in a 12dimensional space (the "NDVI hyperspace"), and all seasonal NDVI patterns belonging to a given habitat class (or to the study area) define a point pattern in the NDVI hyperspace. Note that we have to switch here between two parallel spaces: the location of a pixel in the two-dimensional geographical space and the seasonal
NDVI pattern of the pixel, which represents a point in the 12-dimensional NDVI space.

To measure the distance between two points $k$ and $l$ in the NDVI hyperspace, we generalized Euclidean distance:

$$
d(k, l)=\sqrt{\frac{1}{12} \sum_{\text {month }=1}^{12}\left[\mathrm{NDVI}_{k}(\text { month })-\mathrm{NDVI}_{l}(\text { month })\right]^{2}} .
$$

Because the seasonal NDVI pattern of a given pixel characterizes average ecosystem functioning within this pixel, the distance $d(k, l)$ is a measure of the distance in ecosystem functioning between the two pixels $k$ and $l$. We based our analyses on the univariate distribution $h_{i, i}(d)$ of interpoint distances $d$ between all pairs of points of a given habitat class $i$ and the bivariate distribution $h_{i, j}(d)$ of distances between all pairs of points of classes $i$ and $j$.

\section{Separating the component of "pure" seasonality from total distance in ecosystem functioning}

Our distance metric $d(l, k)$ (Eq. 1) describes the total distance in the seasonal NDVI patterns between two pixels $l$ and $k$, but it is unable to discern between pixels that are different because of mean value or because of seasonal variability. In Appendix C, we show that the distance component $d_{\mathrm{m}}$ associated with mean NDVI is given by the difference of the mean NDVI of the two pixels $k$ and $l$, i.e., $d_{\mathrm{m}}(k, l)=\overline{\mathrm{NDVI}}_{k}-\overline{\mathrm{NDVI}}_{l}$, and that the distance component $d_{\mathrm{s}}$ associated with "pure" seasonality is given by

$$
d_{\mathrm{s}}(k, l)=\sqrt{d(k, l)^{2}-d_{\mathrm{m}}(k, l)^{2}} .
$$

This enables us to calculate the importance of seasonality relative to mean NDVI as $d_{\mathrm{s}} / d_{\mathrm{m}}$.

\section{Accounting for spatial autocorrelation}

Looking at the spatial arrangement of habitat quality (Fig. 1), it seems obvious that the best quality pixels are just spatially nested within poorer habitat pixels and a nested similarity would be expected by the spatial arrangement of pixels and spatial autocorrelation in the seasonal NDVI pattern. To rule this out, we weighted the distance $d(k, l)$ obtained from Eq. 1 with a factor that accounted for correlation between the distance $d(k, l)$ in NDVI hyperspace and the Euclidean distance, determined by linear regression using the data of all pairs of points between the two classes investigated (see Appendix D).

\section{Hypothesis testing}

The seasonal NDVI pattern of one pixel represents one point in the 12-dimensional NDVI hyperspace, and the seasonal NDVI patterns of all pixels of a given class represent a point pattern in the NDVI hyperspace. We can therefore use techniques of point-pattern analysis to 
test our hypotheses. In Appendix C (Fig. C1), they are schematically visualized in a two-dimensional projection of the 12-dimensional NDVI hyperspace.

Hypothesis 1: habitat selection.-To test that the species indeed selects habitat with specific patterns of ecosystem functioning, we used the null hypothesis that the species used the landscape at random with respect to the seasonal NDVI patterns. Translated into the terminology of point-pattern analysis, this means that the $n_{i}$ points of class $i$ were a random sample of the points of the study area, as opposed by "clustering," which would indicate that bears selected specific seasonal NDVI patterns that aggregate in the NDVI hyperspace, conditionally on the points of the study area (Appendix C: Fig. C1A).

The appropriate null model for this situation is univariate random labeling (Wiegand and Moloney 2004). The test is devised by randomly resampling sets of $n_{i}$ points from the points of the study areas to generate the confidence limits. However, because the habitat classes were in the geometrical space not necessarily random samples of the study region, but autocorrelated to some extent (Fig. 1), we included an additional rule to preserve the spatial structures of the habitat classes in their observed form (otherwise spatial autocorrelation might bias the estimation of the confidence limits; Clifford et al. [1989]). A practical method to construct a randomization $i \mathrm{R}$ of class $i$ is a random displacement of all pixels of class $j$ with the same random distance and direction in the geographical space that creates a random subset of $n_{i}$ points in the NDVI hyperspace. We accepted a random displacement of class $i$ if all pixels were within the area of the two populations (i.e., inside the two rectangles in Fig. 1) and outside the Atlantic Ocean.

We assessed significance of a possible departure from the null model by using the mean (NDVI) distance $\bar{h}_{i, i}$ between points of class $i$ as test statistic. We then compared $\bar{h}_{i, i}$ with the mean (NDVI) distance $\bar{h}_{i, i \mathrm{R}}$ between the points of class $i$ and the points of a randomization $i \mathrm{R}$ of class $i$. The theoretical expectation for the null model is $\bar{h}_{i, i}=\bar{h}_{i, i \mathrm{R}}$, and for clustering we expect $\bar{h}_{i, i}<\bar{h}_{i, i \mathrm{R}}$ because smaller distances $d$ would be more frequent. To construct confidence limits of the null model, we performed 999 Monte Carlo simulations and used the fifth and 50th smallest values of $\bar{h}_{i, i \mathrm{R}}$ as $0.5 \%$ and 5\% confidence limits, respectively (Diggle 2003).

Hypothesis 2: ordered relation between ecosystem functioning and habitat quality.-Our hypothesis was that the average distance $\bar{h}_{i, j}$ in ecosystem functioning between pixels of two habitat classes $i$ and $j$ should increase if the differences in habitat quality between class $i$ and $j$ increase (Appendix C: Fig. C1B). To test if there was a significant difference in ecosystem functioning between classes $i$ and $j$, we contrasted our data with the null hypothesis that we cannot distinguish between the seasonal NDVI patterns of pixels of the two classes
(Appendix C: Fig. C1B). Translated into the terminology of point-pattern analysis, this means that the points of "class $i$ " and "class $j$ " were randomly labeled.

The appropriate null model for this situation is random labeling (Wiegand and Moloney 2004). The test is devised by randomly resampling sets of $n_{i}$ points from the $n_{i}+n_{j}$ points of the joined pattern to generate the confidence limits.

In accordance with the hypothesis, we used the average distance $\bar{h}_{i, j}$ between points of class $i$ and points of class $j$ as test statistic and compared $\bar{h}_{i, j}$ with the average distance $\bar{h}_{i \mathrm{R}, j \mathrm{R}}$ between the resampled classes $i \mathrm{R}$ and $j \mathrm{R}$. The theoretical expectation under random labeling is $\bar{h}_{i, j}=\bar{h}_{i \mathrm{R}, j \mathrm{R}}$. We used the fifth largest $\bar{h}_{i \mathrm{R}, j \mathrm{R}}$ as $0.5 \%$ confidence limits around the null model, and the 50 th largest as $5 \%$ confidence limits.

Hypothesis 3: segregation vs. nested similarity.-To distinguish segregation and nested similarity (Appendix C: Fig. C1B, C), we used the data generated for testing the first and second hypotheses. Under nested similarity, we expected a systematic increase in the mean distance $\bar{h}_{i, i}$ between points of class $i$ with decreasing habitat quality. The best class should show the strongest (and significant) habitat selection in the NDVI hyperspace, and habitat selection of the poorest class may be only weakly or not significant. Under segregation, we expected for all classes a significant habitat selection in the NDVI hyperspace, and that the point patterns of two classes would not overlap (for an illustration, see Appendix C: Fig. C1C). Thus, small distances $d$ should be rare in the bivariate distribution $h_{i, j}(d)$, but frequent (i.e., similar to $h_{i, i}(d)$ ) under nested similarity.

\section{Marginality and specialization}

Hypothesis 1 compares the seasonal NDVI patterns that are available at the study area with those actually selected by brown bears. The concepts of marginality and specialization, borrowed from ecological nichefactor analysis (Hirzel et al. 2002), may thus provide additional insight into our data. To this end, we compared the NDVI distance distribution $h_{i, i}(d)$ between all points of the selected class $i$ (i.e., the species distribution) with the NDVI distance distribution $h_{i, i \mathrm{R}}(d)$, which represent the availability (i.e., global distribution). Following Hirzel et al. (2002), the focal species may show some marginality (expressed by the fact that the species mean differs from the global mean) and some specialization (expressed by the fact that the species variance is lower than the global variance). We defined marginality $(M)$ and specialization $(S)$ in analogy to Hirzel et al. (2002) as $M=\left|m_{G}-m_{S}\right| / 1.96 \sigma_{\mathrm{G}}$ and $S=\sigma_{\mathrm{G}} / \sigma_{\mathrm{S}}$, where $m_{\mathrm{G}}$ and $\sigma_{\mathrm{G}}$ are the mean and standard deviation of the global distribution, respectively, and $m_{\mathrm{S}}$ and $\sigma_{\mathrm{S}}$ are the mean and standard deviation of the species distribution. Weighting marginality by $1.96 \sigma_{\mathrm{G}}$ ensures that it most often will be between 0 and 1 . If the global distribution is normal, the marginality of a randomly chosen cell has only a $5 \%$ 
chance of exceeding unity (Hirzel et al. 2002). A large value of $M$ (close to 1 ) thus means that the class is a very particular habitat relative to the reference set. A randomly chosen set of pixels is expected to have a marginality of 0 and a specialization of 1 . Any value of $S$ exceeding unity indicates some form of specialization (Hirzel et al. 2002).

\section{Ordinal logistic regression}

To determine the properties of the seasonal NDVI pattern that determined differences among sequentially nested habitat classes, we performed three ordinal logistic regression analyses (McCullagh and Nelder 1983), one for the data of each subpopulation, and one for the data of the entire population. Our variables were the 12 temporal averages $\mathrm{NDVI}_{i}$ (month) of the NDVI composites between 1987 and 2001 at month $1, \ldots 12$, and pixel $i$ and their corresponding larger-scale variable for the spatial scales $r=1, \ldots 4$. Habitat types were ordered from 1 (best habitat with frequent reproduction) to 5 (extinct). To evaluate which months and scales explained this ordination best, we performed a variablereduction approach combining stepwise ordinal logistic regression and best subset selection based on a secondorder Akaike's Information Criterion index $\left(\mathrm{AIC}_{\mathrm{c}}\right)$ (Burnham and Anderson 1998, Shtatland et al. 2001).

We first constructed a full stepwise sequence for each of the spatial scales ( 0 to 4$)$ at each population (western, eastern, and both together). Preliminary analyses showed that the inclusion of scales higher than 4 did not significantly improve the fit to the data. Additionally, because the inclusion of more than three variables decreased $\mathrm{AIC}_{\mathrm{c}}$ only in fewer than seven units in 10 of the 12 stepwise sequences (a small improvement, according to Burnham and Anderson [1998]), we limited the maximum number of variables to three kept in the final stepwise procedures. This benefited the interpretation of simple exploratory equations with a minimal loss of information. Finally, we compared alternative models with the lowest $\mathrm{AIC}_{\mathrm{c}}$ at the different spatial scales. For each population, we selected the scale and model that produced a better fit to the data in terms of $\mathrm{AIC}_{\mathrm{c}}$. If the difference among scales was $\Delta \mathrm{AIC}_{\mathrm{c}}<7$, we provided information about alternative models.

\section{RESULTS}

\section{Seasonal NDVI patterns of best brown bear habitat and of dominant vegetation types}

Fig. 2A shows the type of ecosystem functioning where brown bears of the western population reproduced regularly and its variability for the 11 best pixels. Ecosystem functioning was characterized by relatively low NDVI values during the winter (December-April when females are denning and give birth), and showed a steep increase in spring (May/June) and a pronounced maximum in summer and early autumn (July-September). Note that the main hyperphagia period of brown bears is September-October. The main food resources of brown bears during the hyperphagia period are berries (Vaccinium myrtillus), other pulpy fruits (Rhamnus alpinus), acorns (Quercus spp.), beechnut (Fagus sylvatica), and chestnut (Castanea sativa) (Naves et al. 2006). The seasonal NDVI patterns of the best $25-\mathrm{km}^{2}$ pixels of the western population were very similar to those of pixels with the highest percentage of deciduous forest (Fig. 2C), but differed starkly from those of pixels with a high percentage of matorral (Fig. 2E), reforestations (Fig. 2G), and pastures (Fig. 2I), which have higher values in winter and early summer.

For the eastern population, the type of ecosystem functioning where brown bears reproduced regularly (Fig. 2B) was similar to that for the western population, but more variable (cf. Fig. 2A, B). It was similar to some pixels of deciduous forest (Fig. 2D) and matorral (Fig. $2 \mathrm{~F}$ ). Note that the typical matorral for the area of the eastern population is not heathlike, but rather scrubland similar to young forest. Differences in ecosystem functioning between the best pixels of the eastern and western populations reflect the overall poorer habitat conditions of the eastern population (Naves et al. 2003, 2006) and differences in climate (see Methods: Study area and populations).

\section{Hypothesis $H_{1}$ : brown bears select habitat with a particular ecosystem functioning}

Western population.-Comparison of the NDVI distance distributions $h_{1,1}$ and $h_{1,1 \mathrm{R}}$ shows that the NDVI distances between pixels of class 1 were particularly low compared to the NDVI distances between pixels of class $i$ and pixels of the entire study region (Fig. 3A). Our statistical test revealed that the pixels selected for all classes were significantly clustered in the NDVI hyperspace (Table 1: $H_{1}$ ), thus confirming hypothesis $H_{1}$.

Eastern population.-Pixels of the classes with reproduction were significantly clustered in the NDVI hyperspace (Table 1: $H_{1}$ ), supporting hypothesis $H_{1}$. The finding that classes 3 and 4 (observations only) did not show a significant selection with respect to ecosystem functioning is consistent with earlier work showing that the eastern population is situated in areas of suboptimal habitat (Naves et al. 2003). A notable exception from the overall trend shown at the western population is that pixels of the class with recent extinctions (e5) were significantly clustered in the NDVI hyperspace (Table 1: $H_{1}$ ).

Total population.-Analysis of the entire population showed that habitat selection was highly significant for classes with reproduction and extinction, and significant for the classes with observations only (Table 1, Fig. 3). These result clearly confirmed hypothesis $H_{1}$.

\section{Hypothesis $\mathrm{H}_{2}$ : larger average difference in ecosystem functioning between two classes imply larger differences in habitat quality}

Western population.-The mean NDVI distance $\bar{h}_{i, j}$ between different classes $i$ and $j$ showed the hypothesized 

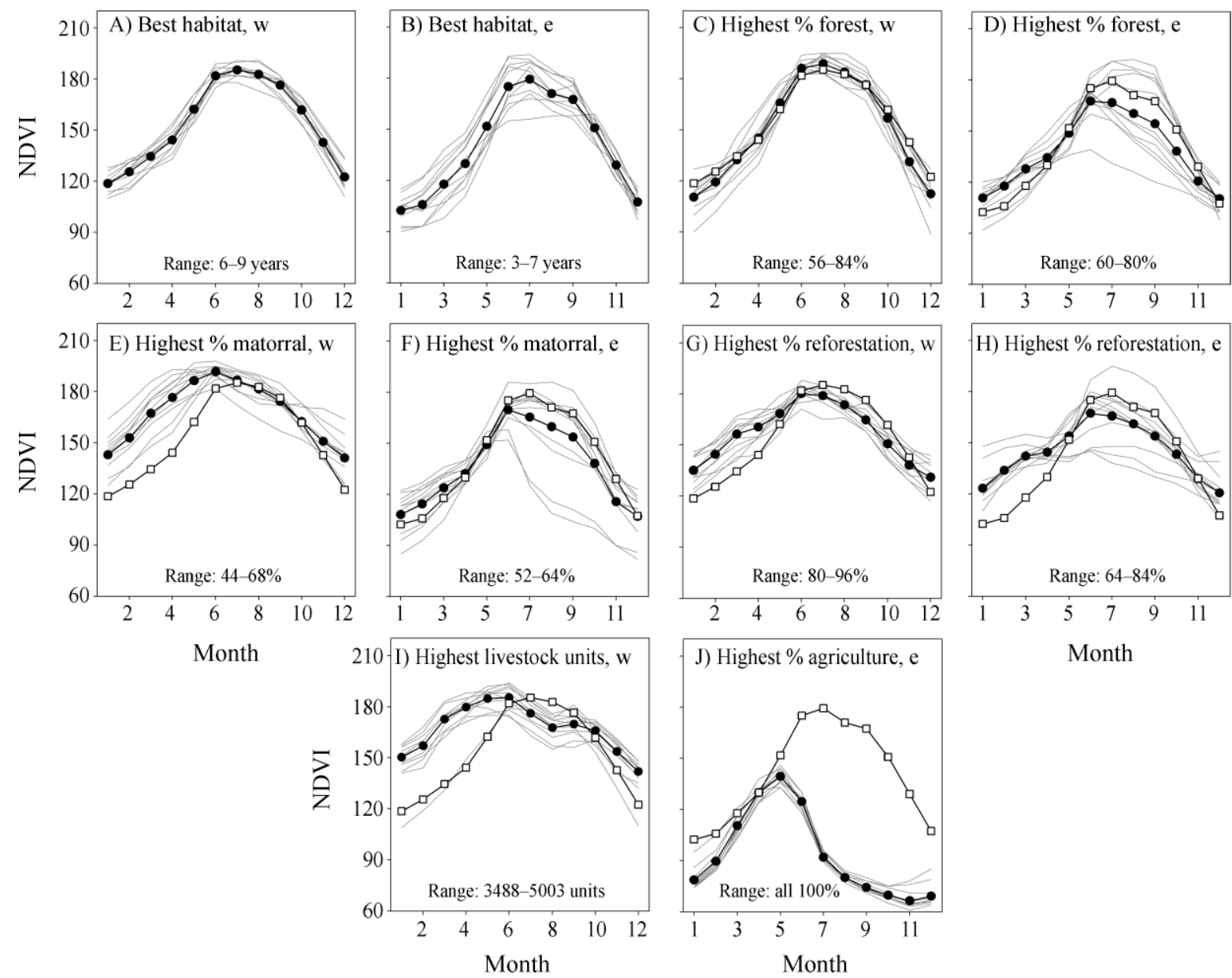

Month

FIG. 2. The seasonal NDVI (normalized difference vegetation index) pattern for best habitat cells and for different vegetation types, separately for the western population (w) and the eastern population (e) of brown bears, taken over the 11 pixels with (A, B) the highest number of years with reproduction (i.e., best habitat cells), and $(\mathrm{C}-\mathrm{G})$ the highest percentage of the vegetation type in the pixel. Additionally, we show the average seasonal NDVI pattern (black circles) and the average NDVI patterns of the best habitat cells (open squares). Month 1 is January. The NDVI is a unitless satellite-derived spectral index calculated from reflectance of vegetation in the near infrared and red spectrum that is linearly correlated with the fraction of photosynthetically active radiation (PAR) intercepted by vegetation. Values $<100$ indicate non-vegetated surfaces. Livestock units, used as a surrogate for grassland, are the number of livestock within $25-\mathrm{km}^{2}$ pixels, weighted by a feed requirement coefficient (e.g., 1 for dairy cows, 0.1 for sheep).

tendency: $\bar{h}_{i, j}$ increased with increasing $j$ (Table 1: $H_{2}$ ). Our statistical test revealed that these tendencies were not always significant, but the class with frequent reproduction was significantly different from classes with observations and recent extinction, and the class with sporadic reproduction was significantly different from classes with sporadic observations and recent extinctions.

Eastern population.- Results obtained for the eastern population (Table 1: $\mathrm{H}_{2}$ ) supported the tendencies found for the western population. The general findings hold equal (except for the extinct class), but the overall differences between classes with current bear presence were not significant. However, the mean NDVI distances $\bar{h}_{i, 5}$ between extinction (class 5) and classes with current bear presence $(i=1-4)$ were significant.
Western vs. eastern population.-Seasonal NDVI patterns of classes of the western population were significantly different from those of the eastern population (except the pairs e5-w5, w3-e3, and w3-e5; Table 1: $\mathrm{H}_{2}$ ), including most pairs of the same class. This is not surprising, because a previous study showed that the two populations exist under different conditions: the eastern population mainly occupies areas of suboptimal habitat, whereas the western population is located mainly in areas with good habitat quality (Naves et al. 2003). The area occupied by the eastern population (mainly located in the southern slope of the Cantabrian Mountain) is under the influence of the mediterranean phytoclimatic region, whereas the western population (mainly located in the northern slope) is under the influence of the 
Class 1
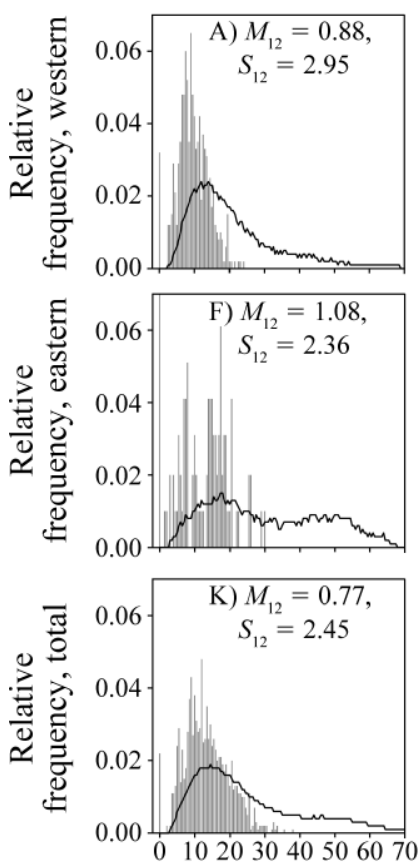

700010203040506070
Class 2
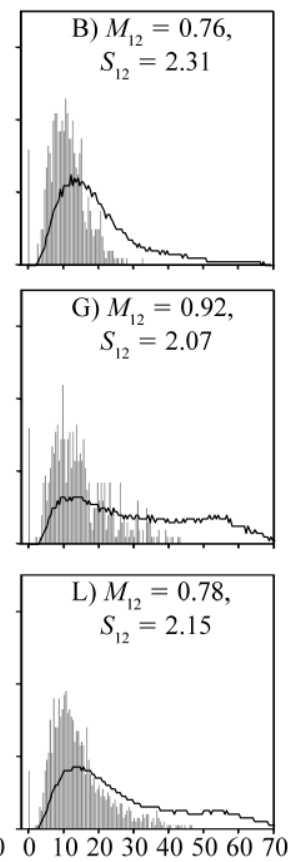

Class 3
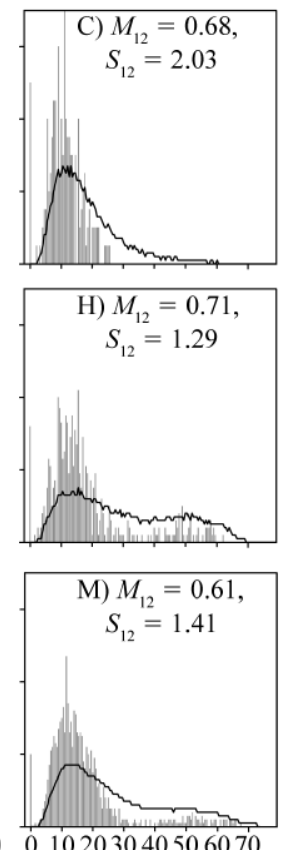

Class 4

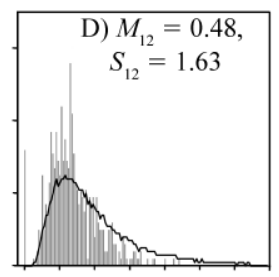

I) $M_{12}=0.65$, $S_{12}=1.53$
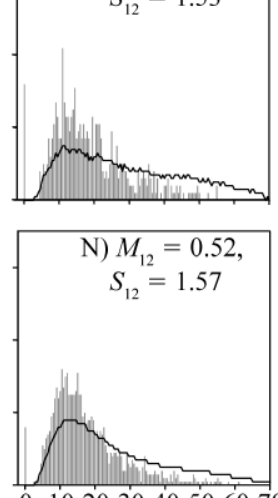

$0 \quad 10203040506070010203040506070$

\section{NDVI distance, $d(k, l)$}

FIG. 3. Univariate analyses for hypothesis $H_{1}$. Shown are the frequency distributions $h_{i, i}(d)$ of NDVI distances $d(k, l)$ between all pairs of points $k$ and $l$ of a given habitat class $i$ (histogram bars, species distribution) and the accumulated distribution $h_{i, i \mathrm{R}}$ of all 999 simulations of the null model for hypothesis $H_{1}$ (solid black line, global distribution). Distributions are shown, by row, for the western, eastern, and total populations of the brown bear. We used $h_{i, i}$ (species distribution, based on points selected by the species) and $h_{i, i \mathrm{R}}$ (global distribution, based on points available to the species) to define marginality $(M)$ and specialization $(S)$ of the ecosystem functioning of selected pixels relative to the ecosystem functioning of the available pixels. Here, $h_{i, i \mathrm{R}}$ is the bivariate distribution of NDVI distances between all pairs of the classes $i$ and $i \mathrm{R}$, where $i \mathrm{R}$ is a random subset of points in the NDVI hyperspace with the same number of points as class $i$. Habitat suitability classes $(i)$ are: class 1, frequent reproduction; class 2 , sporadic reproduction; class 3, no reproduction but frequent observations; class 4, no reproduction but sporadic observations; and class 5 , recent extinction.

TABLE 1. Test of hypotheses $H_{1}$ and $H_{2}$ for classes $1-5$ of the western (w), eastern (e), and total (t) population of the brown bear (Ursus arctos) in northern Spain.

\begin{tabular}{|c|c|c|c|c|c|c|c|c|c|c|c|c|c|c|c|}
\hline Hypothesis & w1 & w2 & w3 & w4 & w5 & el & e2 & e3 & e4 & e5 & $\mathrm{t} 1$ & $\mathrm{t} 2$ & t3 & $\mathrm{t} 4$ & t5 \\
\hline$H_{1}$ & $9.9 * *$ & $11.3^{* *}$ & $11.1^{* *}$ & $13.9 *$ & $15.8^{*}$ & $12.6^{* *}$ & $14.8 *$ & 17.8 & 19.0 & $12.3 * *$ & $13.5^{* *}$ & $14.1^{* *}$ & $17.0^{*}$ & $17.6^{*}$ & $14.5^{* *}$ \\
\hline \multicolumn{16}{|l|}{$\mathrm{H}_{2}$} \\
\hline w1 & & 11.2 & $11.5^{*}$ & $14.0^{* *}$ & $14.7 * *$ & $18.0^{* *}$ & $16.3^{* *}$ & $18.4^{* *}$ & $20.0 * *$ & $11.9^{*}$ & & & & & \\
\hline w2 & & & 12.2 & $13.9 * *$ & $15.2^{* * *}$ & $16.1^{* *}$ & $15.2 * *$ & $17.0^{* *}$ & $18.6^{* *}$ & $12.8^{*}$ & & & & & \\
\hline w3 & & & & 12.3 & 14.5 & $18.3^{* *}$ & $17.0^{* * *}$ & 18.2 & $19.5^{*}$ & 12.6 & & & & & \\
\hline w4 & & & & & 15.6 & $17.8^{* *}$ & $17.0 * *$ & $17.8^{* *}$ & $18.8 * *$ & $14.5^{*}$ & & & & & \\
\hline w5 & & & & & & $19.8^{* *}$ & $18.6^{* *}$ & $19.6^{* *}$ & $20.6^{* *}$ & 15.0 & & & & & \\
\hline el & & & & & & & 14.7 & 16.8 & 17.6 & $18.5^{* *}$ & & & & & \\
\hline e2 & & & & & & & & 17.0 & 17.9 & $16.9^{* *}$ & & & & & \\
\hline e3 & & & & & & & & & 18.0 & $18.6^{* *}$ & & & & & \\
\hline e4 & & & & & & & & & & $20.0^{* *}$ & & & & & \\
\hline $\mathrm{t} 1$ & & & & & & & & & & & & 14.3 & 16.2 & $17.2 *$ & $15.1^{*}$ \\
\hline $\mathrm{t} 2$ & & & & & & & & & & & & & 16.0 & $16.8^{* *}$ & $15.8^{* *}$ \\
\hline $\mathrm{t} 3$ & & & & & & & & & & & & & & 17.6 & $16.9^{* *}$ \\
\hline $\mathrm{t} 4$ & & & & & & & & & & & & & & & $17.6^{* *}$ \\
\hline
\end{tabular}

Notes: Given are the values and the significance of the test statistics $\bar{h}_{i, i}$ (mean NDVI distance between points of class $i$; e.g., w1w1) for $H_{1}$, and $\bar{h}_{i, j}$ (mean distance in ecosystem functioning between pixels of habitat classes $i$ and $j$; e.g., w1-e2) for $H_{2}(* P<$ 0.05 ; ** $P<0.01$ ). Class $i$ : class 1 , frequent reproduction; class 2 , sporadic reproduction; class 3 , no reproduction but frequent observations; class 4 , no reproduction but sporadic observations; and class 5 , recent extinction. 
Eurosiberian phytoclimatic region (Rivas-Martínez 1984).

Interestingly, the mean NDVI distances $\bar{h}_{5, j}$ of the extinct class of the eastern population and the highest three classes of the western population were relatively small $(<13)$ and only marginally significant $(P<0.05)$ or not significant, again confirming the special status of class e5. The reason for this is that the best classes of the western population, as well as the extinct class of the eastern population, are situated at the northern slopes of the Cordillera Cantabria (Fig. 1) and should therefore show a similar ecosystem functioning. This result confirmed an earlier finding that the extinct area of the eastern population is situated in an area of high habitat quality, but suffers a high human impact that probably caused extinction (Naves et al. 2003).

Total population.-Mean NDVI distance $\bar{h}_{i, j}$ between different classes $i$ and $j$ showed the hypothesized tendency: $\bar{h}_{i, j}$ increased with increasing $j$, except for the extinct class (Table 1: $\mathrm{H}_{2}$ ). Our statistical test revealed that these tendencies were not always significant and were somewhat weaker than for the western population. However, the class with extinction was significantly different from all classes with current bear presence.

\section{Hypothesis $H_{3 \mathrm{i}}$ : nested similarity vs. segregation}

Results from testing hypothesis $H_{1}$ confirmed our expectations for nested similarity (with the exception of the extinct class of the eastern and total population). We found for both subpopulations, as well as for the entire population, a systematic increase in the mean distance $\bar{h}_{i, i}$ with decreasing habitat quality (Table 1). Additionally, habitat selection for poorer classes became weaker (Table 1): classes with reproduction were highly significant, but classes $\mathrm{w} 5$, e3, and e4 were not significant. Finally, looking at the distribution of NDVI distances between pairs of pixels between the best class (class 1, frequent reproduction) and classes $1,2 \ldots 5$ showed that the frequency of small distances decreased for both subpopulations gradually from class 1 to class 5 and was even more or less constant for the entire population (Appendix E: Fig. E1). In the case of segregation, we would expect a discontinuous decrease of small distances from $\mathrm{cl}-\mathrm{cl}$ to $\mathrm{cl}-\mathrm{ci}, i=2, \ldots 5$, because $\mathrm{cl}-\mathrm{c} 1$ represents the NDVI distances within the best class (which are low, following hypothesis $H_{1}$ ) and c1-ci represents the NDVI distances between disjunctive classes. The evidence for nested similarity was somewhat weaker for the eastern than for the western population.

\section{Marginality and specialization}

Hypothesis 1, western population.-Breeding females selected pixels with high specialization $(S=2.95$ and $S=$ $2.31)$ and marginality $(M=0.88$ and 0.76$)$, which clearly supported hypothesis 1 . With decreasing habitat quality, specification and marginality decreased monotonously to values of $S=1.61$ and $M=0.38$ for the class of recent extinction (Fig. 3A-E). However, these values were larger than the values $S=1$ and $M=0$ expected for random selection.

Hypothesis 1, eastern population.-Fig. 3F, G shows that breeding females selected, in accordance with hypothesis $H_{1}$, a very particular habitat, with respect to the seasonal NDVI pattern, having high specialization $(S=2.36$ and $S=2.07)$ and high marginality $(M=$ 1.08 and $M=0.92$ ). A notable exception was the class with recent extinctions (class 5), which showed values of specification of $S=3.12$ and marginality of $M=1.05$ (Fig. 3J), similar to those of the classes with frequent reproduction.

Hypothesis 1, total population.-Results for the entire population (Fig. $3 \mathrm{~K}-\mathrm{O}$ ) parallel the tendencies found for the two subpopulations.

Hypothesis 3, nested similarity vs. segregation.Results of the niche analyses clearly supported our hypothesis of nested similarity $\left(H_{3 \mathrm{i}}\right)$, because marginality and specialization decreased systematically with degreasing habitat quality in most cases (Fig. 3; Appendix E: Fig. E1). Under segregation, however, we would expect high marginality and specialization for all habitat classes.

\section{Separating the component of "pure" seasonality from total distance in ecosystem functioning}

Table 1 shows the average distance in ecosystem functioning $[d(k, l)]$ between pixels of all pairs of habitat classes $k$ and $l$. For each of these pairs, we calculated the seasonality component $d_{\mathrm{s}}$ and the component $d_{\mathrm{m}}$ associated with mean NDVI, and the quotient $d_{\mathrm{s}} / d_{\mathrm{m}}$ that describes the relative importance of seasonality compared to mean NDVI.

Fig. 4 shows that differences in seasonality and mean NDVI, on average, contributed equally to total distance in ecosystem functioning; however, seasonality was more important if the total distance was small, and less important if it was larger. Differences in seasonality were especially important among classes 1 , 2 , and 3 in the western population and the extinct class e5 in the eastern population. This is an important result that justifies our approach of analyzing the full seasonal NDVI pattern instead of using only mean NDVI to describe static properties such as average annual energy.

\section{Spatial autocorrelation}

The autocorrelation between the geographical distance of two pixels and the NDVI distance remained surprisingly low. The maximum $R^{2}$ value of the linear regressions was 0.27 for the pair e1-e1, yielding a correlation coefficient of $r=0.52$ (Appendix D: Table D1). Only the pairs e1-e1, t1-t1, w5-w5, w3-w3, and w1-w1 showed a correlation coefficient $r>0.4$ (w, western population; e, eastern population; $t$, total population). A complete listing of all correlation coefficients is shown in Appendix D: Table D1. Spatial 


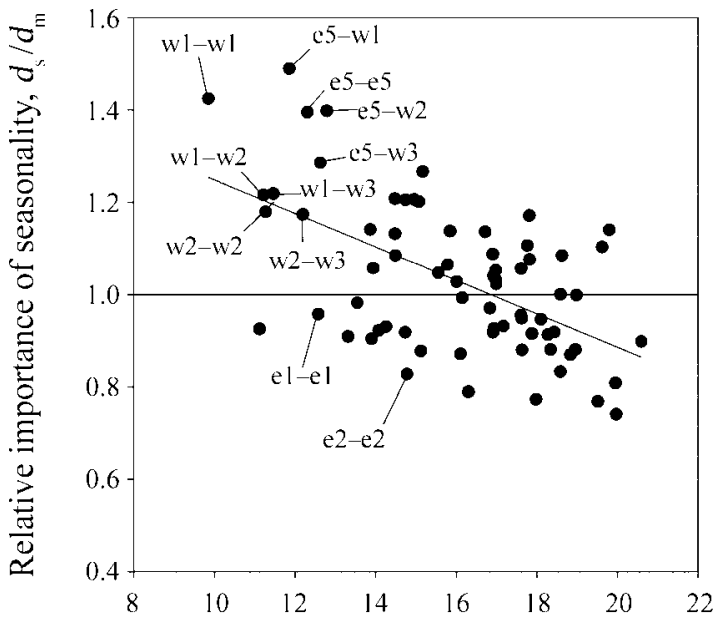

Total mean difference in ecosystem functioning, $d$

FIG. 4. The relative importance of seasonality $\left(d_{\mathrm{s}}\right)$ and mean NDVI $\left(d_{\mathrm{m}}\right)$. We decomposed the distance metric $d$ (measuring the total mean distance in ecosystem function between pixels of two habitat classes $k$ and $l$ ) into the two orthogonal components, the seasonality component $\left(d_{\mathrm{s}}\right)$ and mean NDVI component $\left(d_{\mathrm{m}}\right)$. Where $d_{\mathrm{s}} / d_{\mathrm{m}}>1$, differences in seasonality were more important than differences in mean NDVI; where $d_{\mathrm{s}} / d_{\mathrm{m}}<1$, differences in mean NDVI were more important. Shown are the values of $d_{\mathrm{s}} / d_{\mathrm{m}}$, for all pairs of classes appearing in Table 1, plotted against the value of $d$. Labels represent the pair of classes to which each point corresponds, with numerals indicating class $i$; e.g., e5-w1 is the pair class 5 (recent extinction) of the eastern population and class 1 (frequent reproduction) of the western population.

autocorrelation in ecosystem functioning thus cannot explain our findings of nested similarity.

\section{Ordinal logistic regression: which NDVI variables determine differences among classes?}

Ordinal logistic regression analyses found significant models confirming that differences among habitat classes were determined by differences in NDVI variables, and that our habitat classes followed a sequential order. In general, the neighborhood variables (which capture effects at scales above the $25-\mathrm{km}^{2}$ pixel size) produced better models than variables that considered only NDVI values at the local $25-\mathrm{km}^{2}$ scale. We found the highest correlations between habitat class and NDVI variables at spatial scales $=3$ for the eastern population and spatial scales $=4$ for the western population (Table 2). This result indicates that presence and reproduction of brown bears was influenced by factors operating at the spatial scale of their home range and above. $\mathrm{AIC}_{\mathrm{c}}$ estimates for scales $\geq 2$ were very similar and did not allow assessing which specific scale was the best; however, results clearly showed that habitat evaluation for this species, in terms of ecosystem functioning, must include at least spatial scales $\geq 2$, i.e., neighbored areas $\geq 325 \mathrm{~km}^{2}$.
The best model for the western population had a negative coefficient for the NDVI in June and positive coefficients for September and October (Table 2). This indicates that a better habitat class was characterized by seasonal NDVI patterns with lower values in June and higher values in autumn. For the eastern population, March replaces June as the month with a negative coefficient and June and December replace September and October as the months with a positive coefficient, but the general findings are similar: high habitat quality classes correspond to low relative NDVI values in late winter and early spring and to higher values in late summer and autumn.

TABLE 2. Summary of best equations relating habitat quality to monthly NDVI in each population.

\begin{tabular}{|c|c|c|c|c|c|}
\hline Model & $\begin{array}{c}\text { Standardized } \\
\text { parameter } \\
\text { estimate }\end{array}$ & $\begin{array}{c}P \\
\text { ChiSq }\end{array}$ & $\mathrm{AIC}_{\mathrm{c}}$ & $\Delta \mathrm{AIC}_{\mathrm{c}}$ & $D^{2}$ \\
\hline \multicolumn{6}{|c|}{ Western population } \\
\hline Null model & & & 470.3 & 69.8 & \\
\hline West, $r=4$ & & & 400.5 & & 16.6 \\
\hline Jun4 & -1.59 & $<0.001$ & & & \\
\hline Sep4 & 1.46 & $<0.001$ & & & \\
\hline Oct4 & 0.69 & 0.019 & & & \\
\hline \multicolumn{6}{|c|}{ Eastern population } \\
\hline Null model & & & 447.8 & 81.0 & \\
\hline East, $r=3$ & & & 366.8 & & 20.0 \\
\hline Mar3 & -2.541 & $<0.001$ & & & \\
\hline Jun3 & 0.448 & 0.001 & & & \\
\hline Dec3 & 1.607 & $<0.001$ & & & \\
\hline East, $r=4$ & & & 368.1 & 1.3 & 19.8 \\
\hline Mar4 & -2.667 & $<0.001$ & & & \\
\hline Jun4 & 0.262 & 0.048 & & & \\
\hline Dec4 & 1.786 & $<0.001$ & & & \\
\hline \multicolumn{6}{|c|}{ Total population } \\
\hline Null model & & & 916.3 & 81.3 & \\
\hline Total, $r=2$ & & & 837.5 & 2.5 & 9.4 \\
\hline Mar2 & -1.138 & $<0.001$ & & & \\
\hline Sep2 & 0.313 & $<0.001$ & & & \\
\hline Dec2 & 0.842 & $<0.001$ & & & \\
\hline Total, $r=3$ & & & 835.0 & & 9.7 \\
\hline Mar3 & -1.399 & $<0.001$ & & & \\
\hline Jul3 & 0.273 & $<0.001$ & & & \\
\hline Dec3 & 1.115 & $<0.001$ & & & \\
\hline Total, $r=4$ & & & 839.8 & 4.8 & 9.1 \\
\hline Mar4 & -1.476 & $<0.001$ & & & \\
\hline Sep4 & 0.228 & 0.001 & & & \\
\hline Dec4 & 1.236 & $<0.001$ & & & \\
\hline Total, $r=2$ & & & 837.5 & 2.5 & 9.4 \\
\hline Mar2 & -1.138 & $<0.001$ & & & \\
\hline Sep2 & 0.313 & $<0.001$ & & & \\
\hline
\end{tabular}

Notes: Variable names in column 1 refer to the month and neighborhood size (radius of 2, 3, or 4 pixels). Neighborhood values are the average value of the corresponding variable $\mathrm{NDVI}_{i}$ (month) taken within a circular neighborhood of radius $r$ [no. pixels] around pixel i. $P$ ChiSq is the chi-square probability that the parameter is significant. $\mathrm{AIC}_{\mathrm{c}}$ is the second-order Akaike information criterion. $\triangle \mathrm{AIC}_{\mathrm{c}}$ is the increase in the $\mathrm{AIC}_{\mathrm{c}}$ score with respect to the smallest score for the corresponding population. $D^{2}$ is the deviance explained by the fitted regression. 

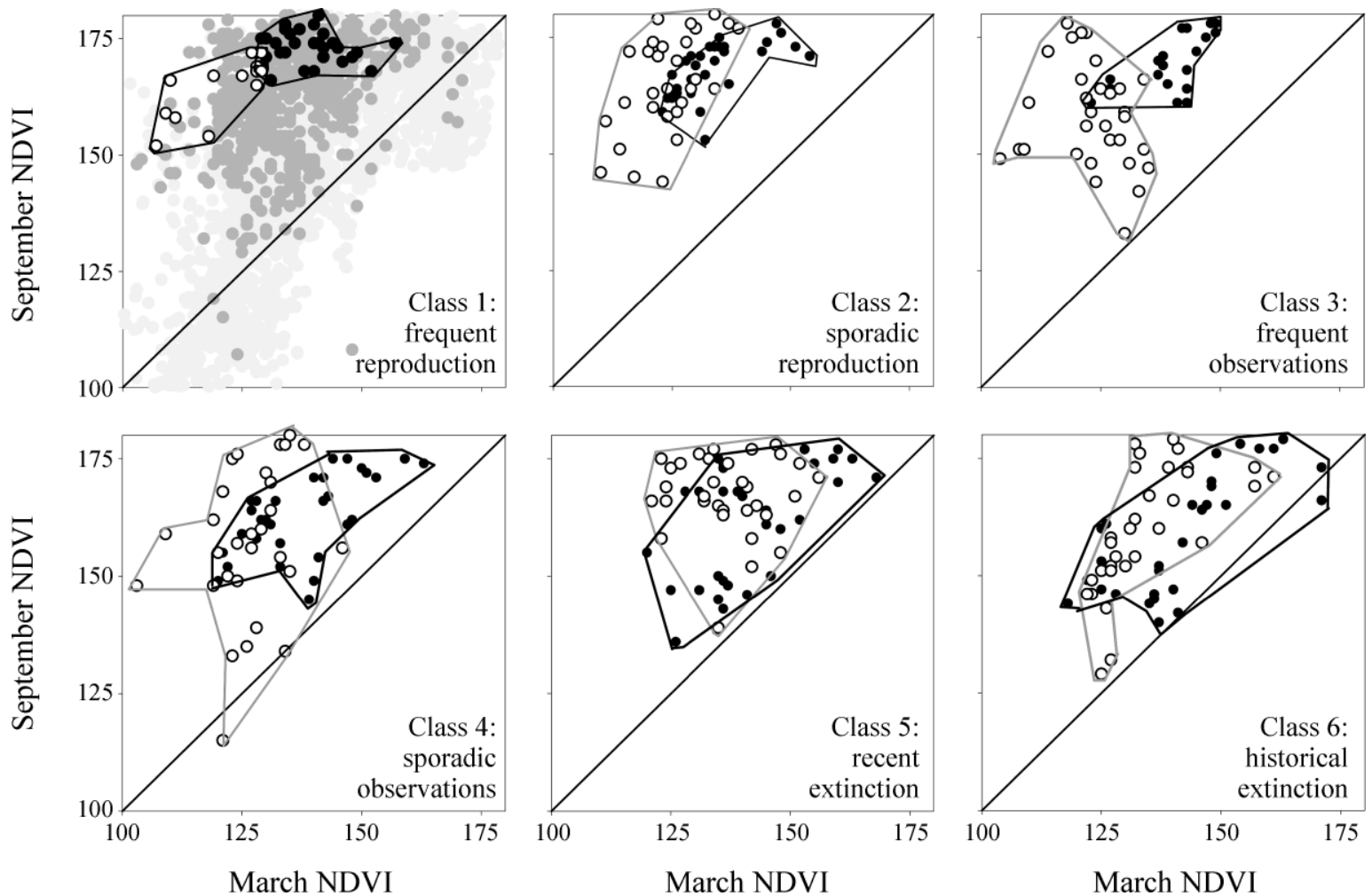

FIG. 5. Visualization of the seasonal NDVI patterns of the different classes within a two-dimensional space of ecosystem functioning, spanned by March NDVI and September NDVI, both at scale 2 (i.e., a $325-\mathrm{km}^{2}$ area surrounding the location of the pixel). Open circles represent the eastern bear population; solid circles represent the western population. Polygon lines delineate the area covered by the points of the eastern and western populations, the dark gray dots in the graph for class 1 show the 599 points of pixels with contemporary and historic bear presence, and the light gray dots show the points of the entire study area (Fig. 1).

\section{DisCUSSION}

We found that brown bears in northern Spain did indeed select habitat with a particular ecosystem functioning, and they did this in a specific way that we termed nested similarity. Although previous studies have addressed analogous relationships at large biogeographical scales when looking at the distribution of the species (Ferguson 2002, Nilsen et al. 2005), few have focused before on local scales of habitat selection and quality.

The essence of our findings can be illustrated at a lower dimensional representation of the 12-dimensional NDVI hyperspace (Fig. 5). We used March NDVI and September NDVI, calculated as the average from a 325$\mathrm{km}^{2}$ area surrounding the location of interest, as the two axes of this representation. These two variables yielded the most parsimonious ordinal logistic regression model to separate the observed classes of habitat quality of the entire population (Table 2). We interpreted the resulting two-dimensional space spanned by these two variables as a simplified representation of an ecosystem functioning hyperspace perceived by brown bears, because March NDVI was related to winter mildness and September NDVI was related to peak production (see Discussion: Brown bear biology, seasonality, and nested similarity). In accordance with this scheme, areas of high seasonality (i.e., low productivity in March and high productivity in September) were located in the upper left corner of this hyperspace (above the one-to-one line); the one-to-one line (i.e., the diagonal in Fig. 5) indicates no seasonality.

The points of the classes with frequent reproduction were clustered in the high-seasonality corner of the ecosystem functioning hyperspace, whereas poorer classes occurred, in an approximately nested way, within a much broader range of ecosystem functioning (Fig. 5). Habitat with the most excessive needs (i.e., breeding habitat) occupied the narrowest niche with respect to ecosystem functioning (strongest clustering in the NDVI hyperspace), whereas habitat selection of progressively poorer classes became weaker, occupying wider, but partly overlapping, niches (progressively weaker clustering).

\section{Brown bear biology, seasonality, and nested similarity}

For many species, it has been shown that breeding phenology (i.e., timing of conception and parturition) is closely related to temporal variation in food availability (e.g., Wittemyer et al. 2007). Ecosystem functioning of breeding habitat (Fig. 2A, B) showed three main characteristics that are tightly related to the breeding phenology of brown bears. First, it shows a bottleneck 
with low values in the winter months, December to March, when pregnant females are hibernating and giving birth (see Discussion: The bottleneck). Second, it shows a steep increase during the spring months, April to June. This increase in productivity coincides with the moment when females with newborn cubs usually leave the den (Naves and Palomero 1993), and with the mating season (Fernández-Gil et al. 2006). Third, ecosystem functioning shows a pronounced maximum in summer and early autumn (June-September). The major food categories in summer are herbs, berries, and other pulpy fruits (Naves et al. 2006), and extensive consumption of dry fruits such as acorns, beechnuts, and chestnuts in autumn is critical for pregnant females that will hibernate during winter (Naves et al. 2006). In the following, we discuss in more detail the implications of each of these characteristics for brown bear biology.

Hyperphagia and denning.-Brown bear reproduction relies, with hibernation and hyperphagia, on two specific evolutionary adaptations to energy bottlenecks and pulses, respectively. For example, Pearson (1975) found that brown bears may gain up to $640 \mathrm{~g}$ body mass per day, and they may spend up to $17-18 \mathrm{~h} / \mathrm{d}$ foraging on berries during the hyperphagia period (Welch et al. 1997). Food availability during the hyperphagia period is critical for reproductive success. Bears experience "delayed implantation" so that the fertilized egg (blastocyst) does not begin to develop before the female bear enters the den. If the female cannot accumulate enough fat reserves, the embryo will not implant (Hissa 1997). Denning is an essential procedure for female brown bears and their reproductive success; adult females will give birth to and suckle offspring while denning. Fasting thus coincides with a period when they must sustain the nutritional demands of gestation and the first 2-3 months of lactation, as well as meeting their own metabolic requirements. Not surprisingly, brown bears can lose up to $43 \%$ of their fall body mass during the denning period (reviewed in Schwartz et al. 2003). Interestingly, the physiological condition of hibernation is not readily, or is intermittently, attained in response to fluctuating weather, but is probably due to involvement of a neurocircumannual cycle (Folk et al. 1976). For example, pregnant females in Sweden entered their dens before snowfall, when berries were still available and abundant (Friebe et al. 2001). With this background, it is reasonable to assume that reproduction occurred in the Cantabrian Mountains, when viewed on a regional scale with grain of $25 \mathrm{~km}^{2}$, only in areas with very specific ecosystem functioning that matched the "eccentric" energy needs of breeding females, offering just the right timing for the peak in productivity. On the other hand, nonbreeding animals can afford to be somewhat less selective, thereby producing the observed pattern of nested similarity.

The bottleneck.-However, not only the peak in productivity is important, but also the bottleneck. This is illustrated by the ordinal logistic regression analysis, which showed that inclusion of NDVI months with a negative coefficient improved the models significantly. The average NDVI composite of March appeared consistently in all plausible models constructed for the entire population. On the first view, this result seems counterintuitive because increasing productivity should increase food availability and thus habitat quality. However, in the Cantabrian Mountains, March is the last month of winter and breeding females and their offspring do not terminate denning before mid-April. Therefore, March NDVI does not measure food availability for females with cubs in March, but is rather an indicator of temperatures (higher temperatures stimulate earlier vegetation growth, which results in higher greenness) and thus of winter mildness. Higher ambient temperatures (as indicated by higher greenness) may increase the energy requirements during hibernation and cause additional stress for hibernating animals. This was recently shown by Humphries et al. (2002), based on a general bioenergetic model for mammalian hibernation, and exemplified by well-quantified hibernation energetics of the little brown bat (Myotis lucifugus).

Looking from the perspective of ecosystem functioning, it is well established that species adapted to a certain energy pulse during a specific time window also need a "negative" pulse at a second time window, and that both pulses are complementary and linked by a feedback mechanism. For example, leaf and flower bud meristems of most temperate woody perennials are formed in the summer and autumn (Saure 1985); to ensure that growth and flowering do not occur until the next spring, plants have developed specific adaptations (vernalization) to detect, to measure, and to "remember" the duration of the winter (Amasino 2004). Recent studies have shown that interruption of this feedback, e.g., by global change, has serious consequences for species and for ecosystem functioning (Linkosalo et al. 2000, Bailey and Harrington 2006). In this respect, it is important to note that the brown bear populations in Spain are located close to the meridional limit of their natural distributional range and, even under "normal" conditions, already are subject to stress.

\section{Ecosystem functioning vs. vegetation structure}

What are the improvements of the approach taken here relative to approaches that use static habitat variables to assess habitat quality (e.g., Mladenoff et al. 1995, Schadt et al. 2002, Naves et al. 2003)? We argued that the temporal distribution of resources (i.e., seasonality) should be of special importance for brown bears, which show along with hibernation, delayed implantation, and hibernation, specific evolutionary adaptations to periods of energy peaks and bottlenecks. Within our framework, we can rephrase the initial question and ask if our finding of nested similarity relies on the component of seasonality or if it can be attributed solely to static habitat variables such as deciduous forest cover, the most important 
vegetation type for brown bears, or average NDVI, which describes average productivity.

We decomposed our measure of total difference in ecosystem functioning into the two orthogonal components representing "pure" seasonality and "pure" average NDVI. Interestingly, we found that both components had approximately the same importance, but seasonality was relatively more important if total distance in ecosystem functioning was smaller. This interesting result supports our hypothesis that the temporal distribution of resources is an important determinant of habitat quality for brown bears. Clearly, we cannot expect that seasonality would solely explain habitat selection, because brown bears need a minimum amount of energy for reproduction (i.e., delayed implantation) and the total NDVI during the hyperphagia period will be correlated with total annual NDVI.

To show that our NDVI variables are at least as successful in predicting brown bear presence as the structural variables used in Naves et al. (2003: Table 2), we repeated their regression analysis for the best model (including the variables forest cover, landscape ruggedness, and number of villages), but we used the NDVI composites for March and September instead of the vegetation structure variables forest cover and landscape ruggedness. Note that this analysis is not completely comparable to our approach taken here because it used all data on bear observations (i.e., classes 1-4) without distinguishing between habitat for reproduction and for presence. Also, pixels in the neighborhood of observations were used as "no observations" to assure that nonobservation areas were those that bears could have visited. The model with the two NDVI variables performed slightly better, as indicated by a difference in $\mathrm{AIC}_{\mathrm{c}}$ of 11.2, and at the 0.5 cut level, it classified $71.5 \%$ of all cases correctly as opposed to $69.5 \%$ reached by the model in Naves et al. (2003). To find out to what extent we can predict bears presence using only NDVI signatures, we also constructed models that included only NDVI variables. The best of those models, at the 0.5 cut level, classified $70.2 \%$ of all cases correctly and included the September NDVI composite with positive sign and mean NDVI with negative sign. Thus, NDVI was able to provide at least the same information as the structural variables. However, introducing both structural and functional variables did not further improve the model.

We used several additional approaches to assess potential correlations between structure and functioning that are described in detail in Appendix F. First, we constructed a variable "sim" that described the distance in ecosystem functioning of a given pixel to ecosystem functioning in the best habitat areas and correlated this variable with several environmental variables (Appendix F: Table F1). Next, we correlated environmental variables with the monthly NDVI composites (Appendix F: Table F1), and finally we repeated the analysis for assessing spatial autocorrelation in ecosystem function- ing, but instead of the distance between two pixels in geographical space, we used the distance in an environmental variable (Appendix D: Table D1). In summary, we found surprisingly weak correlations between ecosystem functioning and vegetation structure variables, and the correlation coefficient exceeded only in a few cases values of 0.5 . Thus, although there is evidently a link between structure and functioning (because vegetation produces greenness that is measured by NDVI), this link is surprisingly weak at our scale of observation and insufficient to "explain" our main findings.

On the first view, however, a somewhat disturbing deficiency of our analysis is that we are left to accept the utility of NDVI for the study area without validation of specific bear foods or other attributes of the habitats reflected by NDVI. Indirect remotely sensed data have been used, for example, for predicting landscapes suitable for grizzly bear habitat (e.g., Mace et al. 1996, 1999, Nielsen et al. 2002, 2003). However, there is little information on what remotely sensed indices actually represent in terms of concrete food items. It therefore would be desirable to investigate whether mechanistic links exist between the seasonal NDVI pattern and bear food items or fitness (Nielsen et al. 2003). However, the correspondence between ecosystem functioning and vegetation structure is, in general, an open question, although it is often assumed (Paruelo et al. 2004).

\section{NDVI, brown bear biology, and global change}

Although the consequences of climatic change on temperature and productivity are difficult to predict, a further increase in winter temperatures is likely to occur in the future (Vicente-Serrano and Heredia-Laclaustra 2004), together with a displacement of the fruit productivity peak from the late summer and autumn (typical for temperate forests) toward a late autumn and winter (typical for mediterranean climate). Pregnant brown bear females are subject to a tight schedule and reproductive success depends basically on their ability to accumulate fat before November. If the timing of peak food supply and the predetermined and restricted schedule of energy demand are mismatched, females may not be able to benefit from a later productivity peak. A similar case, in which climatic change may have decreased the habitat quality of a species with an inflexible phenology schedule, has been observed, for example, for the Mediterranean Pied Flycatcher, a migratory bird breeding in the Mediterranean region (Sanz et al. 2003). They found that reduction of nestling growth and survival of fledged young might be a result of the mismatch between the timing of peak food supply and the nestling demand caused by recent climate change.

Additionally, the Cantabrian Mountains in northwestern Spain constitute one of the southernmost (island-like) refuges of a boreal-like ecosystem (García et al. 2005) and many plant species that form an important part of the brown bear diet (e.g., Vaccinium 
spp., Quercus petraea, Fagus sylvativa) also have their meridional distribution limit in the Cantabrian Mountains. Thus, the ecosystem that provides the best habitat for brown bears can also be expected to be most sensitive. Although our NDVI data, averaged over the pixels of a given class, did not show a significant trend over the 15-year period, the pixels of the different classes showed a mainly decreasing trend in mean NDVI during the hyperphagia period July-November. This negative trend, however, was not significant for the best classes w1 and el ( $P=0.11$ and $P=0.69$, respectively) but paralleled findings of Rodriguez et al. (2007) who investigated 1974-2003 trends in occurrence of major food items of the Cantabrian brown bears during the hyperphagia period. They found that boreal and temperate food items decreasingly contributed to brown bear diet, replaced by increasing contributions of southern foods. This suggests that warmer temperatures might determine the occurrence of some food items in the diet of Cantabrian brown bears through effects on plant distribution and phenology, which may result in a worsening of conditions for the principal food sources of brown bears. Finally, although global warming may disadvantage brown bears, it may favor (non-hibernating) food competitors such as wild and domestic ungulates and may lead to an increase in their populations due to reduced winter constraints. This winter effect would decrease habitat quality for brown bears for the rest of the year.

\section{Conclusions}

We proposed a new way of looking at habitat quality from the angle of ecosystem functioning and provided statistical techniques to quantify the relationship. We argued that habitat selection of resident species adapted to a peak and bottleneck in seasonal energy availability should reflect properties in ecosystem functioning that are related to the biology of the species. Our example of brown bears in northern Spain illustrated that adopting the perspective of ecosystem functioning can provide new insights into the relationships between habitat quality and the biology of the species. Our methodology could be widely applied for animal species living in seasonal environments. The importance of our findings, however, is not so much grounded in having an alternative way of characterizing habitat quality, but our perspective opens doors to answer pressing questions, such as the impact of climatic change on habitat quality, which a conventional analysis using static variables of vegetation structure cannot offer. Changes in ecosystem functioning can be tracked in a direct and quick way by using NDVI data, which are continuously collected with a fine temporal resolution, and can be translated into changes in habitat quality.

\section{ACKNOWLEDGMENTS}

Satellite data were kindly provided by LATUV (Laboratorio de Teledetección-Universidad de Valladolid). We acknowledge the Spanish Ministry of Environment (MIMAM) and the governments of Asturias, Castilla y León, Cantabria, and Galicia for providing data from the official counts of females with cubs and other data. The MIMAN also provided digital cartography about forest cover. G. Baldi helped with remote sensing data processing, and funding provided by the UFZ, and the EBD enabled M.Garbulsky, J. Naves, and T. Wiegand to travel between Spain, Germany, and Argentina for collaborative work. The manuscript benefited from comments by Eloy Revilla, Bill Fagan, and five anonymous referees. J. Naves was supported by the projects Fremd F+E 0302 UFZ-CSIC and Plan Nacional de I+D+I BOS2001-2391-CO2-02 (Ministerio de Educación y Ciencia, Spain).

\section{Literature Cited}

Alcaraz, D., J. Paruelo, and J. Cabello. 2006. Identification of current ecosystem functional types in the Iberian Peninsula. Global Ecology and Biogeography 15:200-212.

Alerstam, T., and A. Hedenström. 1998. The development of bird migration theory. Journal of Avian Biology 29:343-369.

Alfonso XI. 1348. Re-edited 1976. Libro de la Montería. Ediciones Velázquez, Madrid, Spain.

Amasino, R. 2004. Vernalization, competence, and the epigenetic memory of winter. Plant Cell 16:2553-2559.

Andersen, R., I. Herfindal, B. E. Sæther, J. D. C. Linnell, J. Oddén, and O. Liberg. 2004. When range expansion is faster in marginal habitats. Oikos 107:210-214.

Asrar, G., M. Fuchs, E. T. Kanemasu, and J. L. Hatfield. 1984 Estimating absorbed photosynthetic radiation and leaf area index from spectral reflectance in wheat. Agronomy Journal 76:300-306.

Bailey, J. D., and C. A. Harrington. 2006. Temperature regulation of bud-burst phenology within and among years in a young Douglas-fir (Pseudotsuga menziesii) plantation in western Washington, USA. Tree Physiology 26:421-430.

Box, E. O., B. N. Holben, and V. Kalb. 1989. Accuracy of the AVHRR vegetation index as a predictor of biomass, primary productivity and net $\mathrm{CO}_{2}$ flux. Vegetatio 80:71-89.

Boyce, M. S. 1979. Seasonality and patterns of natural selection for life histories. American Naturalist 114:569-583.

Brown, J. H., D. W. Mehlman, and G. C. Stevens. 1995. Spatial variation in abundance. Ecology 76:2028-2043.

Burnham, K. P., and D. R. Anderson. 1998. Model selection and inference: a practical information-theoretic approach. Springer Verlag, New York, New York, USA

Clifford, P., S. Richardson, and D. Hémon. 1989. Assessing the significance of the correlation between two spatial processes. Biometrics 45:123-134.

Craighead, J. J., J. S. Sumner, and J. A. Mitchell. 1995. The grizzly bears of Yellowstone. Their ecology in the Yellowstone ecosystem, 1959-1992. Island Press, Washington, D.C., USA.

Diggle, P. J. 2003. Statistical analysis of spatial point patterns. Second edition. Arnold, London, UK.

Falge, E., et al. 2002. Seasonality of ecosystem respiration and gross primary production as derived from FLUXNET measurements. Agricultural and Forest Meteorology 113:53-74.

Ferguson, S. H. 2002. The effects of productivity and seasonality on life history: comparing age at maturity among moose (Alces alces) populations. Global Ecology and Biogeography 11:303-312.

Fernández-Gil, A., J. Naves, and M. Delibes. 2006. Courtship of brown bears Ursus arctos in northern Spain: phenology, weather, habitat and durable mating areas. Wildlife Biology 12:367-373.

Folk, G. E., Jr., A. Larson, and M. A. Folk. 1976. Physiology of hibernating bears. International Conference on Bear Research and Management 3:373-380.

Friebe, A., J. E. Swenson, and F. Sandegren. 2001. Denning chronology of female brown bears in central Sweden. Ursus $12: 37-46$

García, D., M. Quevedo, J. R. Obeso, and A. Abajo. 2005. Fragmentation patterns and protection of montane forest in 
the Cantabrian range (NW Spain). Forest Ecology and Management 208:29-43.

Garel, M., E. J. Solberg, B. E. Sæther, I. Herfindal, and K. A. Høgda. 2006. The length of growing season and adult sex ratio affect sexual size dimorphism in moose. Ecology 87: $745-758$.

Goward, S. N., R. H. Waring, D. G. Dye, and J. Yang. 1994. Ecological remote sensing at OTTER: satellite macroscale observations. Ecological Applications 4:322-343.

Greenwood, J. J. D., R. D. Gregory, S. Harris, P. A. Morris, and D. W. Yalden. 1996. Relations between abundance, body-size and species number in British birds and mammals. Philosophical Transactions of the Royal Society of London B 351:265-278.

Hellgren, E. C. 1998. Physiology of hibernation in bears. Ursus 10:467-477.

Herfindal, I., J. D. C. Linnell, J. Odden, E. B. Nilsen, and R. Andersen. 2005. Prey density, environmental productivity and home-range size in the Eurasian lynx (Lynx lynx). Journal of Zoology 265:63-71.

Herrera, C. M. 1978. On the breeding distribution pattern of European migrant birds: MacArthur's theme reexamined. Auk 95:496-509.

Hirzel, A. H., J. Hausser, D. Chessel, and N. Perrin. 2002. Ecological-niche factor analysis: how to compute habitatsuitability maps without absence data? Ecology 83:20272036.

Hissa, R. 1997. Physiology of the European brown bear (Ursus arctos arctos). Annales Zoologici Fennici 34:267-287.

Hobbs, T. J. 1995. The use of NOAA-AVHRR NDVI data to assess herbage production in the arid rangelands of Central Australia. International Journal of Remote Sensing 16:1289 1302.

Humphries, M. M., D. W. Thomas, and J. R. Speakman. 2002. Climate-mediated energetic constraints on the distribution of hibernating mammals. Nature 418:313-316.

Humphries, M. M., J. Umbanhowar, and K. S. McCann. 2004. Bioenergetic prediction of climate change impacts on northern mammals. Integrative and Comparative Biology 44:152-162.

Hurlbert, A. H., and J. P. Haskell. 2003. The effect of energy and seasonality on avian species richness and community composition. American Naturalist 161:83-97.

Inman, R. M., and M. R. Pelton. 2002. Energetic production by soft and hard mast foods of American black bears in the Smoky Mountains. Ursus 13:57-68.

Kerr, J. T., and M. Ostrovsky. 2003. From space to species: ecological applications for remote sensing. Trends in Ecology and Evolution 18:299-305.

Koenig, W. 1984. Geographic variation in clutch size in the Northern Flicker (Colaptes auratus): support for Ashmole's hypothesis. Auk 101:698-706.

Lindstedt, S. L., and M. S. Boyce. 1985. Seasonality, fasting endurance, and body size in mammals. American Naturalist 125:873-878.

Linkosalo, T., T. R. Carter, R. Häkkinen, and P. Hari. 2000. Predicting spring phenology and frost damage risk of Betula spp. under climatic warming: a comparison of two models. Tree Physiology 20:1175-1182.

Lloyd, D. 1990. A phenological classification of terrestrial vegetation cover using shortwave vegetation index imagery. International Journal of Remote Sensing 11:2269-2279.

Loe, L. E., C. Bonenfant, A. Mysterud, J.-M. Gaillard, R. Langvatn, F. Klein, C. Calenge, T. Ergon, N. Pettorelli, and N. C. Stenseth. 2005. Climate predictability and breeding phenology in red deer: timing and synchrony of rutting and calving in Norway and France. Journal of Animal Ecology 74:579-588.

MacArthur, R. H. 1959. On the breeding distribution pattern of North American migrant birds. Auk 76:318-325.
Mace, R. D., J. S. Waller, T. L. Manley, K. Ake, and W. T. Wittinger. 1999. Landscape evaluation of grizzly bear habitat in western Montana. Conservation Biology 13:367-377.

Mace, R. D., J. S. Waller, T. L. Manley, L. J. Lyon, and H. Zuuring. 1996. Relationships among grizzly bears, roads, and habitat in the Swan Mountains, Montana. Journal of Applied Ecology 33:1395-1404.

Madoz, P. 1846-1850. Diccionario geográfico-estadístico-histórico de España y sus posesiones de ultramar. Volume 16. P. Madoz and L. Sagasti, Madrid, Spain.

Mattson, D. J., B. M. Blanchard, and R. R. Knight. 1991. Food habits of Yellowstone grizzly bears, 1977-1987. Canadian Journal of Zoology 69:1619-1629.

McCullagh, P., and J. A. Nelder. 1983. Generalized linear models. First edition. Chapman and Hall, London, UK.

McLoughlin, P. D., S. H. Ferguson, and F. Messier. 2000. Intraspecific variation in home range overlap with habitat quality: a comparison among brown bear populations. Evolutionary Ecology 14:39-60.

Mladenoff, D. J., T. A. Sickley, R. G. Haight, and A. P Wydeven. 1995. A regional landscape analysis and prediction of favorable gray wolf habitat in the Northern Great Lakes region. Conservation Biology 9:279-294.

Naves, J., A. Fernandez-Gil, C. Rodriguez, and M. Delibes. 2006. Brown bear food habits at the border of its range: a long-term study. Journal of Mammalogy 87:899-908.

Naves, J., and G. Palomero. 1993. El oso pardo (Ursus arctos) en España. Colección Técnica. Instituto Nacional para la Conservación de la Naturaleza (ICONA). Madrid, Spain.

Naves, J., T. Wiegand, A. Fernández, and T. Stephan. 1999. Riesgo de extinción del oso pardo cantábrico: la población occidental. Fundación Oso de Asturias, Oviedo, Spain.

Naves, J., T. Wiegand, E. Revilla, and M. Delibes. 2003. Endangered species balancing between natural and human constraints: the case of brown bears (Ursus arctos) in northern Spain. Conservation Biology 17:1276-1289.

Nielsen, S. E., M. S. Boyce, G. B. Stenhouse, and R. H. M. Munro. 2002. Modeling grizzly bear habitats in the Yellowhead Ecosystem of Alberta: taking autocorrelation seriously. Ursus 13:45-56.

Nielsen, S. E., M. S. Boyce, G. B. Stenhouse, and R. H. M. Munro. 2003. Development and testing of phenologically driven grizzly bear habitat models. Ecoscience 10:1-10.

Nilsen, E. B., I. Herfindal, and J. D. C. Linnell. 2005. Can intraspecific variation in carnivore home-range size be explained using remote-sensing estimates of environmental productivity? Ecoscience 12:68-75.

Nores, C. 1988. Reducción areal del oso pardo en la Cordillera Cantábrica. Acta Biologica Montana. Série Documents de Travail 2:7-14.

Nores, C., and J. Naves. 1993. Distribución histórica del oso pardo en la Península Ibérica. Pages 13-33 in J. Naves and G. Palomero, editors. El oso pardo (Ursus arctos) en España. Colección técnica. Instituto Nacional para la Conservación de la Naturaleza (ICONA), Madrid, Spain.

Osborne, P. E., J. C. Alonso, and R. G. Bryant. 2001. Modelling landscape-scale habitat use using GIS and remote sensing: a case study with great bustards. Journal of Applied Ecology 38:458-471.

Paruelo, J. M., H. E. Epstein, W. K. Lauenroth, and I. C. Burke. 1997. ANPP estimates from NDVI for the Central Grassland Region of the United States. Ecology 78:953-958.

Paruelo, J. M., R. A. Golluscio, J. P. Guerschman, A. Cesa, V. V. Jouve, and M. F. Garbulsky. 2004. Regional scale relationships between ecosystem structure and functioning: the case of the Patagonian steppes. Global Ecology and Biogeography 13:385-395.

Paruelo, J. M., E. G. Jobbagy, and O. E. Sala. 2001. Current distribution of ecosystem functional types in temperate South America. Ecosystems 4:683-698. 
Pearson, A. M. 1975. The northern interior grizzly bear Ursus arctos L. Canadian Wildlife Service Report Series Number 34. Canadian Wildlife Service, Ottawa, Canada.

Pérez-Tris, J., and J. L. Tellería. 2002. Regional variation in seasonality affects migratory behaviour and life-history traits of two Mediterranean passerines. Acta Oecologica 23:13-21.

Pettorelli, N., J.-M. Gaillard, A. Mysterud, P. Duncan, N. C. Stenseth, D. Delorme, G. Van Laere, C. Toïgo, and F. Klein. 2006. Using a proxy of plant productivity (NDVI) to find key periods for animal performance: the case of roe deer. Oikos 112:565-572.

Pettorelli, N., J. O. Vik, A. Mysterud, J.-M. Gaillard, C. J. Tucker, and N. C. Stenseth. 2005. Using the satellite-derived NDVI to assess ecological responses to environmental change. Trends in Ecology and Evolution 20:503-510.

Rivas-Martínez, S. 1984. Pisos bioclimáticos de España. Lazaroa 5:33-43.

Rodriguez, C., J. Naves, A. Fernandez-Gil, J. R. Obeso, and M. Delibes. 2007. Long-term trends in food habits of a relict brown bear population in northern Spain: the influence of climate and local factors. Environmental Conservation 34: $36-44$.

Sanz, J. J., J. Potti, J. Moreno, S. Merino, and O. Frias. 2003. Climate change and fitness components of a migratory bird breeding in the Mediterranean region. Global Change Biology 9:461-472.

Saure, M. C. 1985. Dormancy release in deciduous fruit trees. Horticultural Reviews 7:239-300.

Schadt, S., E. Revilla, T. Wiegand, F. Knauer, P. Kaczensky, U. Breitenmoser, L. Bufka, J. Cerveny, P. Koubek, T. Huber, C. Stanisa, and L. Trepl. 2002. Assessing the suitability of central European landscapes for the reintroduction of Eurasian lynx. Journal of Applied Ecology 39:189-203.

Schwartz, C. C., S. D. Miller, and M. A. Haroldson. 2003. Grizzly bear. Pages 556-586 in G. A. Feldhamer, B. C. Thompson, and J. A. Chapman, editors. Wild mammals of North America: biology, management and conservation. Second edition. Johns Hopkins University Press, Baltimore, Maryland, USA.

Sellers, P. J., C. J. Tucker, G. J. Collatz, S. O. Los, C. O. Justice, D. A. Dazlich, and D. A. Randall. 1994. A global 1 by 1 NDVI data set for climate studies. II. The generation of global fields of terrestrial biophysical parameters from the NDVI. International Journal of Remote Sensing 15:35193545.

Servheen, C. 1990. The status and conservation of the bears of the world. Eighth International Conference on Bear Research and Management. Monograph Series 2:1-32.

Shtatland, E. S., E. Cain, and M. B. Barton. 2001. The perils of stepwise logistic regression and how to escape them using information criteria and the output delivery system. Pages 222-226 in Proceedings of the 26th Annual SAS Users Group International Conference, SAS Institute, Cary, North Carolina, USA.

Stoyan, D., and H. Stoyan. 1994. Fractals, random shapes and point fields. Methods of geometrical statistics. John Wiley, Chichester, UK.

Torrente, J. P. 1999. Osos y otras fieras en el pasado de Asturias (1700-1860). Fundación Oso de Asturias, Oviedo, Spain.

Vicente-Serrano, S. M., and A. Heredia-Laclaustra. 2004. NAO influence on NDVI trends in the Iberian peninsula (19822000). International Journal of Remote Sensing 25:28712879.

Weiner, J. 1992. Physiological limits to sustainable energy budgets in birds and mammals: ecological implications. Trends in Ecology and Evolution 7:384-388.

Welch, C. A., J. Keay, K. C. Kendall, and C. T. Robbins. 1997. Constraints on frugivory by bears. Ecology 78:1105-1119.

Wiegand, T., and K. A. Moloney. 2004. Rings, circles and nullmodels for point pattern analysis in ecology. Oikos 104:209229.

Wiegand, T., J. Naves, T. Stephan, and A. Fernandez. 1998. Assessing the risk of extinction for the brown bear (Ursus arctos) in the Cordillera Cantabrica, Spain. Ecological Monographs 68:539-571.

Wittemyer, G., H. Rasmussen, and I. Douglas-Hamilton. 2007. Breeding phenology in relation to NDVI variability in freeranging African elephant. Ecography 30:42-50.

Zinner, D., F. Pelaez, and F. Torkler. 2002. Distribution and habitat of grivet monkeys (Cercopithecus aethiops aethiops) in eastern and central Eritrea. South African Journal of Ecology 40:151-158.

\section{APPENDIX A}

Observation and reproduction data and construction of habitat classes from data on habitat use (Ecological Archives M078-004A1).

\section{APPENDIX B}

NDVI data (Ecological Archives M078-004-A2).

\section{APPENDIX C}

Determination of the seasonal component in the total NDVI distance metric and illustration of the three hypotheses (Ecological Archives M078-004-A3).

\section{APPENDIX D}

Accounting for spatial autocorrelation (Ecological Archives M078-004-A4).

\section{APPENDIX E}

Figures showing nested similarity vs. segregation (Ecological Archives M078-004-A5).

\section{APPENDIX F}

Vegetation structure vs. functioning (Ecological Archives M078-004-A6). 